\title{
MORADORES-EM-AÇÃO: CONSTITUIÇÃO DA PAISAGEM NO BAIRRO RIBEIRÃO VERDE, EM RIBEIRÃO PRETO, SP
}

\author{
DWELLERS IN ACTION: BUILDING THE LANDSCAPE \\ AT THE RIBEIRÃO VERDE AREA, IN RIBEIRÃO PRETO, SP
}

Laura Barzaghi de Laurentiis

Eng. Agrônoma (ESALQUSP), mestre em Paisagem e Ambiente (FAUUSP)

e-mail: lauralaurentiis@uol.com.br

\section{RESUMO}

Este artigo foi baseado na dissertação de mestrado defendida na FAUUSP, trata-se dos problemas constituídos pela conjunção do crescimento das cidades sobre áreas periféricas ambientalmente frágeis, da ocupação dessas áreas por uma população desenraizada do espaço e não pertencente ao lugar e da formação de sentido de paisagem, por alguns moradores que, mediante ações paisagísticas pontuais - apropriações particularizadas do espaço livre do bairro - constroem laços afetivos, um sentido de identidade e a própria paisagem do lugar.

Palavras-Chave: Paisagem - Ribeirão Preto (SP), Paisagem - Formação, Assentamentos humanos, Periferia, Áreas de conservação

\begin{abstract}
This article is based on master's thesis defended at FAUUSP ANDdeals with attempts at landscape building in peripherical housing settlements in an environment-sensitive area, through specific actions of a group of dwellers - the dwellers in action. The study attempted to unravel the process of value formation regarding the landscape space by means of different ways of space appropriation.
\end{abstract}

Keywords: Landscape Ribeirão Preto (SP), Landscape - Shaping, Housing settlements, Periphery, Preservation areas

\section{INTRODUÇÃO}

Neste trabalho trata-se dos problemas constituídos pela conjunção do crescimento das cidades sobre áreas periféricas ambientalmente frágeis, da ocupação dessas áreas por uma população desenraizada do espaço e não pertencente ao lugar e da formação de sentido de uma paisagem, por alguns moradores que, mediante ações paisagísticas pontuais - apropriações particularizadas do espaço livre do bairro - constroem laços afetivos, um sentido de identidade e a própria paisagem do lugar.

Para tanto, considerou-se o bairro Ribeirão Verde, na periferia da cidade de Ribeirão Preto, interior de São Paulo.

problema em questão origina-se com a construção de dois loteamentos de interesse social em uma área rural, desprovida de infraestrutura, distante do centro da cidade (e fora do tecido urbano), e ambientalmente sensível, por ser área de recarga do aquífero Guarani. 
Tem início aí a polêmica em torno da aprovação dos loteamentos, envolvendo o Conselho Municipal do Meio Ambiente (COMDEMA), organizações não governamentais (ONGs) ambientalistas, representantes da sociedade civil e o Ministério Público, que solicitou a paralisação das obras por entender que a construção dos loteamentos era irregular uma vez que não tinham as aprovações necessárias em nível administrativo estadual.

Como consequência da intervenção do Ministério Público foram feitas uma série de exigências técnicas pelos órgãos responsáveis para a aprovação dos loteamentos. Entre estas se destacam: o cercamento, a preservação e a conservação da mata, a recuperação e a proteção dos fragmentos florestais da área de proteção permanente (APP) do córrego das Palmeiras, a implantação de 208.390,39 m² de área verde em forma de praças, além da arborização viária e a criação de um programa de educação ambiental que auxiliasse na redução do impacto ambiental causado pela urbanização.

Os benefícios das medidas compensatórias, do ponto de vista ambiental, são claros; além da preservação e da conservação dos fragmentos de vegetação nativa, da recuperação e do reflorestamento da área de proteção permanente (APP) do córrego das Palmeiras, as áreas verdes implantadas também garantiriam a permeabilidade do solo, abrigo para fauna local, benéficos do ponto de vista do microclima, além de seus potenciais recreativos e estéticos. No entanto, as dificuldades da implantação dessas medidas não se encontram só em sua execução, mas principalmente em sua manutenção.

Em relação à mata e à área de preservação permanente (APP), o fato de estarem sob proteção legal não significa qualquer tipo de garantia de sua conservação, ou mesmo sobrevivência. A mata foi cercada para que não houvesse qualquer tipo de uso. No entanto, foram inúmeros os incêndios que a atingiram. $\bigcirc$ último, ocorrido em agosto de 2008, durante o andamento desta pesquisa, queimou extensa superfície e causou severos danos à vegetação.

Percebe-se, assim, que a manutenção destas áreas de preservação e mesmo das áreas verdes em geral dependem da existência de uma certa receptividade pelos moradores em relação às mesmas. Como exemplo do que se afirmou, em um quadro de abandono geral das áreas destinadas como "sistema de lazer" no bairro estudado, destacam-se parcelas cuidadas por moradores, os "moradores-em-ação". O que motiva tais práticas? $\bigcirc$ que elas representam? $\bigcirc$ que revelam? Seria possível pensar na formação de uma "sensibilidade paisagística" decorrente das ações praticadas pelos moradores-em-ação?

Diante do problema exposto, desenvolveu-se uma pesquisa dentro do campo teórico da Percepção Ambiental, onde se propôs desvelar a relação entre os moradores-em-ação e o ambiente do bairro Ribeirão Verde, para verificar a formação de valores paisagísticos.

Aqui vale delimitar as noções de paisagem e percepção utilizadas neste trabalho. Entende-se paisagem como expressão sensível da relação do homem com seu ambiente de vida (milieu), e, portanto, inseparável do olhar que a constitui e de uma realidade física. Nem uma projeção do sujeito sobre o objeto, nem um objeto autônomo em si, 
exterior ao sujeito; a paisagem se revela numa experiência em que o sujeito e objeto são inseparáveis (DARDEL, 1990; BERQUE, 2000). Já percepção ultrapassa o significado meramente sensorial e inclui vários aspectos como cognição, imaginário, significado, avaliação e valoração. Esse sentido mais amplo do termo está de acordo com os estudos de Percepção Ambiental, aqui tomados como referência. Nessa posição, o ambiente não é entendido só como fonte de estímulos ou informações sensoriais, derivadas de suas propriedades intrínsecas (arquitetural, espacial, funcional, etc.), mas inclui elementos simbólicos, normativos e oportunidades de ações, além de um sistema de relações sociais. Esses fatores se tornam constitutivos do ambiente, primeiro por meio de uma atribuição de significado socialmente partilhada De modo semelhante, as pessoas são partes constituintes de contextos sociais, culturais e ambientais e têm respostas variadas não só por suas características individuais, mas também em relação às suas posições no contexto social.

A partir dessas considerações, os objetivos estabelecidos neste estudo foram:

- verificar as formas de percepção e apropriação de um espaço que não tem "histórico" para seus moradores;

- estudar os meios pelos quais a identidade e os laços afetivos com o lugar se dão no tempo;

- contribuir para o desenvolvimento de um método de aproximação das questões que envolvem a apropriação de espaços e a constituição de paisagens.

Em busca da consecução dos objetivos descritos foi feita uma pesquisa empírica no bairro Ribeirão Verde. As estratégias para coletas de dados foram escolhidas em categorias metodológicas propostas por White (1978), baseadas no ouvir, no observar e no perguntar, triangulação metodológica que objetiva abranger a máxima amplitude na descrição, na explicação e na compreensão do objeto de estudo.

\section{RIBEIRÃO VERDE}

O bairro Ribeirão Verde é resultado de uma parceria com a iniciativa privada para a construção de 3.461 lotes urbanizados $A$ área escolhida para o empreendimento foi a fazenda Santa Maria, com 1.555.823,16 m², distante 17 quilômetros do centro de Ribeirão Preto e localizada no bairro das Palmeiras, que está situado a leste da rodovia Anhanguera, no setor leste do município, pertencendo à microbacia do córrego das Palmeiras, à margem esquerda do rio Pardo.

Z Zoneamento Ambiental de Ribeirão Preto define a área em questão como ZUE 1 - Zona de Uso Especial - caracterizada por sua localização sobre a área de ocorrência das formações geológicas Botucatu e Piramboia. Por suas características geológicas de contato com o aquífero subterrâneo, a legislação prevê: maior controle em relação às possíveis contaminações da água, que abastece 100\% da cidade, bem como resguarda suas áreas de infiltração, garantindo a recarga do lençol freático.

A vegetação natural da área do bairro e suas adjacências consistem em: um fragmento de Floresta Mesófila ou Estacional Semidecidual com 10 mil m²; a mata do Ribeirão 
Verde; uma pequena mancha de mata ciliar na várzea do córrego das Palmeiras; e a Reserva Legal Mata Sinhá Junqueira fragmento de Floresta Estacional Semidecidual com 550 mil m² de área.

O Sistema de Lazer ocupa uma área de 208.390,39 m² dividida em 25 locais; são rotatórias, canteiros centrais, "praças" e duas grandes áreas: a área " $A$ ", de aproximadamente 55 mil m², cujo destino seria um "parque esportivo"; a área da antiga sede, com 67.497,44 $\mathrm{m}^{2}$, que abrigava o núcleo residencial da antiga fazenda, composto por oito casas, pomar, campo de futebol, parquinho infantil, muito arborizada e vizinha à Mata e à APP.

Algumas praças foram parcialmente arborizadas pelos empreendedores, mas a morte ou retirada das árvores é da ordem de $90 \%$. Até a data deste estudo, nenhuma das áreas de lazer havia sido implantada pela Prefeitura. De algumas, no entanto, cuidam os moradores, que plantam mudas, fazem as regas de manutenção, controle de plantas invasoras, através de capina do terreno e cercamento da área. Como não há pontos de água nessas áreas, os moradores regam as mudas com garrafas "pet", baldes, mangueiras, ou o que for mais adequado.

Essas parcelas de áreas cercadas e cultivadas contrastam com as áreas vizinhas, sem dono e abandonadas, ou ainda com a função de depósito de entulhos, lixo e objetos sem serventia. Das 25 áreas do sistema de lazer, treze "pertencem" a algum morador, que as tomou para cuidar e cultivar. Com esse novo status de "quintal de alguém" passam a exibir uma vegetação densa, plantada em pequeno espaçamento, resultando em bosques e maciços arbóreos, em grande parte formada por frutíferas, na maioria das vezes entremeadas por pés de milho, mandioca, abóbora, hortaliças, legumes, temperos e ervas.

envolvimento de moradores com as áreas verdes do bairro foi percebido por representantes do Programa de Educação Ambiental do Ribeirão Verde (PEARV), que vislumbraram a possibilidade de usá-lo como promotor de comportamento pró-am-

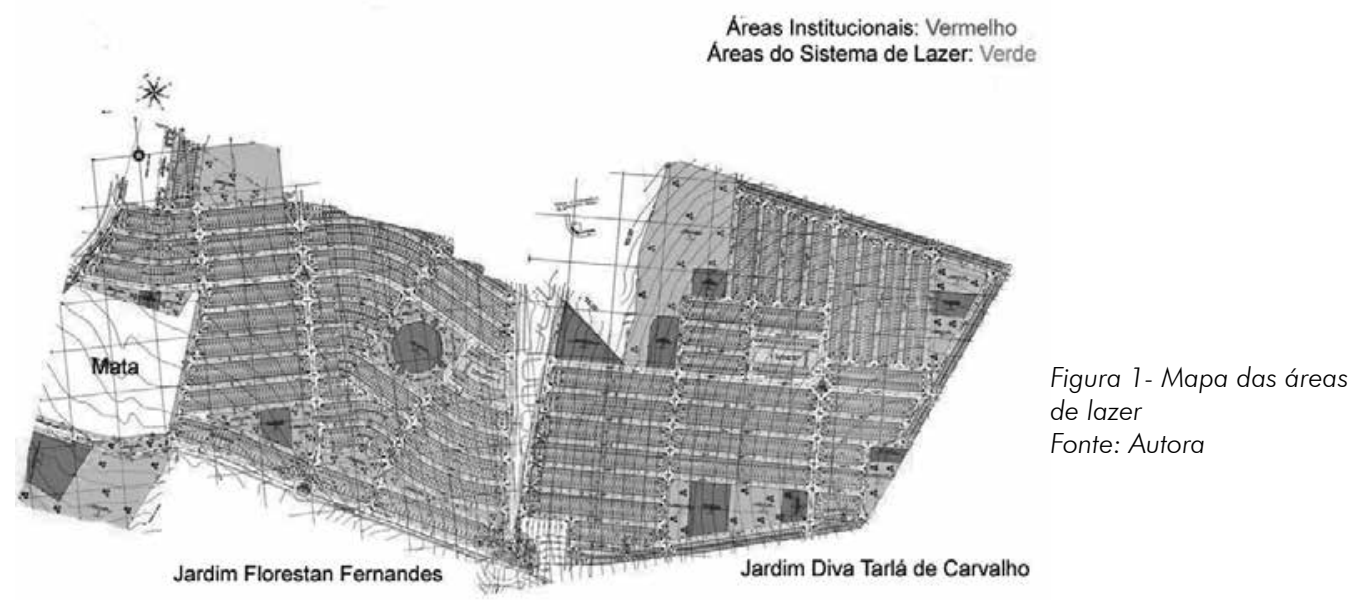


biental. Assim, foi criada uma coluna no informativo mensal do PEARV, O Verdinho, denominada de "Moradores-em-ação" dedicada aos moradores que contribuem, com ações, para a melhoria do bairro.

\section{COLABORADORES DA PESQUISA: MORADORES-EM-AÇÃO}

Dentro do universo empírico foram escolhidos 20 moradores-em-ação como sujeitos da pesquisa. A escolha dos moradores-em-ação justifica-se por possibilitar claramente o universo pesquisado e permitir uma aproximação, ou comparação, com os estudos de Bernard Lassus sobre os "moradores-paisagistas".

Em pesquisas feitas a partir da década de 1960, em regiões suburbanas na França, Bernard Lassus descobriu e identificou uma arte de jardins praticada por alguns moradores. Esses moradores foram denominados moradores-paisagistas, por atribuírem maior importância à elaboração de relações de paisagem do que aos objetos em si. Em seus jardins-paisagens cada objeto tem seu lugar e seu significado em conexão com o outro, estabelecendo uma relação que pode ser chamada de paisagística.

Essas relações são mais ou menos materializadas, em parte visíveis e em parte ocultas, mas que, se não são apreendidas imediatamente, podem vir a ser pelo conhecimento de sua narrativa fundadora (LASSUS, 1977, p. 137). Os jardins-paisagens reúnem duas diferentes escalas: a escala tátil - da proximidade do lugar -, e a visível - da ordem do inatingível, da matéria imaginada, nunca verificada, essas distintas escalas se articulam no imaginário, chave de entendimento das criações dos moradores-paisagistas ${ }^{1}$.

Os moradores-em-ação e os moradores-paisagistas são habitantes da periferia das cidades que, mediante práticas espaciais de jardinagem, criam novas paisagens. Eles "fazem porque gostam", destinam boa parte de seu tempo livre a isso, têm forte envolvimento afetivo com suas criações.

Têm em comum um "estado de insatisfação" com os espaços de origem, ressalvadas as diferentes condições que contribuem para esse estado. A insatisfação transforma-se em práticas de intervenção e modificação do substrato paisagístico ${ }^{2}$ e a criação de um espaço próprio.

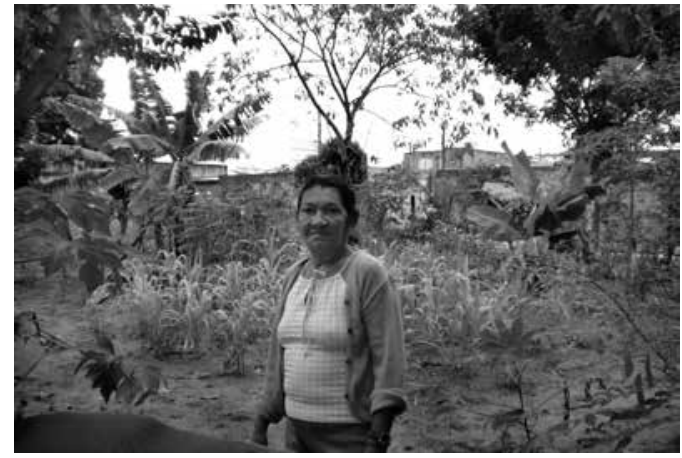

Figura 2 - Área morador-em-ação Fonte: Autora

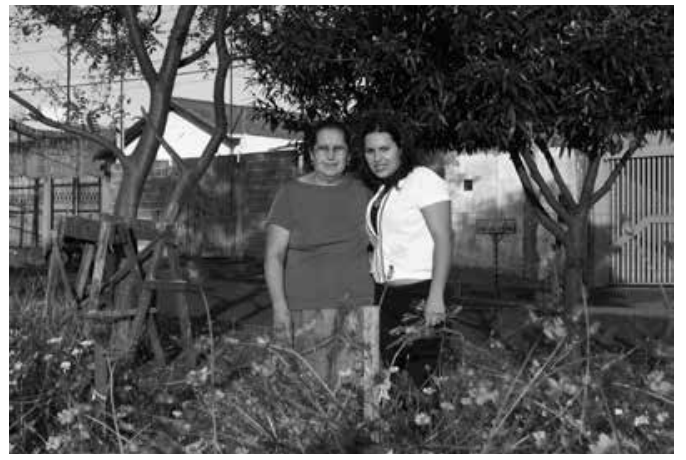

Figura 3 - Área morador-em-ação Fonte: Autora 
Quanto às criações propriamente ditas, o sonho e o imaginário são comuns a ambos os grupos pesquisados. Pode-se afirmar que os moradores-em-ação diferenciam-se dos moradores-paisagistas porque expressam os valores relacionados à paisagem mais verbalmente que in situ. Aqueles não representam as relações paisagísticas materialmente como os moradores-paisagistas franceses, mas são "afetados" por valores ambientais, morais, estéticos, etc., com base em seus aportes no substrato paisagístico.

\section{METODOLOGIA E FUNDAMENTAÇÃO TEÓRICO-CONCEITUAL: "PERCURSO FOTOGRÁFICO"}

O trabalho foi desenvolvido no campo teórico da Percepção Ambiental, fundamentado numa abordagem fenomenológica, uma vez que se busca mais do que uma descrição conceitual, mas, sim, o entendimento de como se configuram as leituras que os sujeitos estabelecem a partir da vivência do lugar.

embasamento para a elaboração e o direcionamento da pesquisa de campo foi obtido com autores que tratam de metodologia de pesquisa e construção de conhecimento, como Dulce Critelli (2006) e Mirian Goldenberg (2005).

O trabalho empírico, realizado entre maio e dezembro de 2008, objetivou verificar a percepção e apropriação do espaço pelos colaboradores da pesquisa-bairro. As estratégias para a coleta de dados foram selecionadas entre categorias metodológicas baseadas no ouvir, no observar e no perguntar, com base na triangulação metodológica proposta por White (1978).

Assim, com o aporte teórico dos autores da psicologia ambiental, como Willian Ittelson (1973) e Amos Rapoport (1978), e autores que estudam o uso de história oral e narrativa dos sujeitos como fonte de dados em pesquisas, como Ecléa Bosi (2004), foi possível elaborar um instrumento de coleta de dados denominado de "Percurso Fotográfico".

Perguntou-se aos colaboradores: "Se algum de seus parentes, que não conhecesse o lugar onde você mora, the pedisse para mandar fotografias do seu bairro, que lugares você fotografaria?" Em seguida, em data combinada com a pesquisadora, solicitava-se que tirassem fotografias dos locais/objetos escolhidos.

A ideia inicial dos "Percursos Fotográficos" era que seriam feitos a pé. Mas alguns fatores, como a dimensão do bairro, as grandes distâncias entre os locais escolhidos, o pouco tempo disponível dos colaboradores e os poucos horários disponíveis destes para colaborar na pesquisa, entre outros, nos levaram a fazê-los de carro.

Foram feitos dezenove "Percursos Fotográficos" com vinte colaboradores 3 . Forneceu-se a câmera fotográfica digital e pretendia-se, no primeiro momento, que os colaboradores fotografassem, o que não ocorreu. Dos dezenove "Percursos Fotográficos" apenas em dois as fotografias foram tiradas por eles. Nos demais casos, dada a resistência dos colaboradores em manusear a câmera sob a alegação de "não saber tirar fotografias", pediu-se a eles que apontassem o enquadramento, o ângulo da fotografia, e, depois de tiradas, as imagens eram mostradas na tela da câmera digital. 
Entre outubro e novembro de 2008 voltou-se a campo para a devolução e discussão das fotografias obtidas no "Percurso Fotográfico" e para aplicação de um "Questionário" (cujo objetivo era ampliar o quadro empírico do trabalho, para obter mais dados sobre percepção, atitudes e valores dos sujeitos da pesquisa).

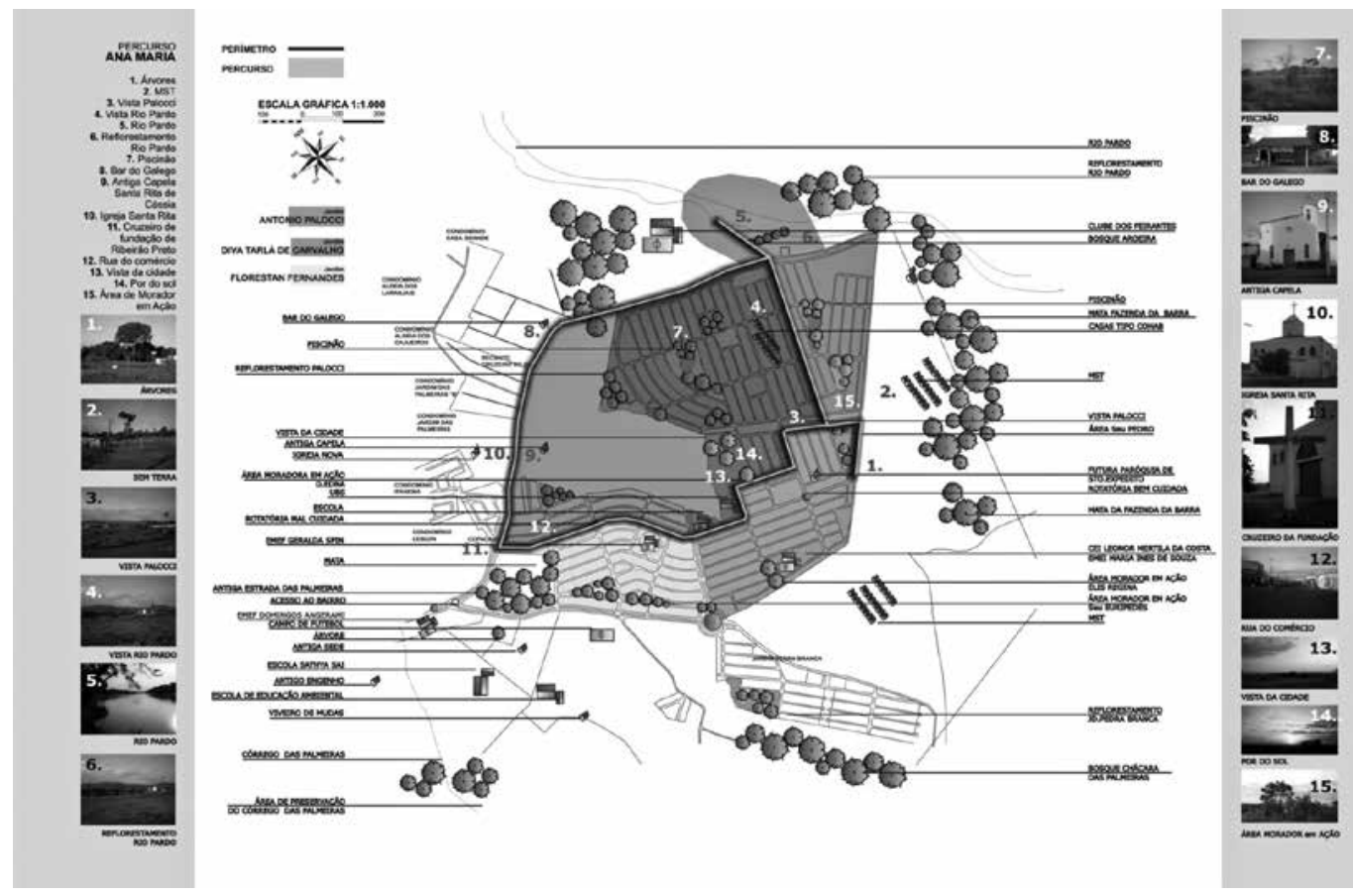

Figura 4 - Mapa de "Percurso Fotográfico" Fonte: Autora

\section{ANÁLISE DO MATERIAL}

\section{A "diferença" do Ribeirão Verde}

bairro Ribeirão Verde é identificado primeiro pela presença de vegetação. Os colaboradores da pesquisa percebem o bairro como um local bem arborizado, com forte presença de "verde". O bairro também é identificado como um local mais fresco, mais arejado, com o ar mais puro e mais úmido que no centro da cidade, qualidades atribuídas, pelos colaboradores, à presença de vegetação.

Também é percebido como um lugar calmo, sossegado, onde se pode ter uma vida mais tranquila, com mais espaço para se viver, "uma sensação de amplidão", de "se ver longe", parecendo que se está em uma "cidadezinha do interior". Ao lado dessa "amplidão de vista e de espaço para se viver" há também uma percepção de acolhimento. É o lugar onde "Tenho a minha casa", afirma um; "Onde criei meus filhos", explica outra; "Eu cresci junto com o bairro", diz a terceira.

Mas, também, é percebido como o lugar do não pertencimento, do abandono, da exclusão dos espaços racionais da cidade luminosa. Por um lado, a carência de 
equipamentos sociais, possibilidades de trabalho e de lazer, Por outro, é lugar dos excessos - de lixo e entulho espalhado nos espaços livres, de queimadas urbanas, de gado solto e de abandono das áreas verdes.

O abandono das áreas verdes, o acúmulo de lixo e de entulho, e as queimadas urbanas, são problemas inter-relacionados, pois se joga entulho e lixo nas áreas "abandonadas" e a solução encontrada para limpar essas áreas, por muitos moradores, é atear fogo nesses terrenos, queimando, consequentemente, vastas áreas e, com elas, as árvores plantadas. Tal encadeamento de acontecimentos é uma realidade desde os primórdios do bairro.

\section{As Geografias Pessoais}

A partir dos dados coletados - fotografias, anotações de campo - foram construídos mapas individuais com informações como o trajeto percorrido, a delimitação espacial do bairro e os marcos referenciais da paisagem fotografados. A intenção era a construção de mapas narrativos, ou seja, representações gráficas que informassem sobre a paisagem percebida por colaborador.

Depois de feitas a análise e a comparação desses mapas individuais, notaram-se certas semelhanças e aproximações de modos de apropriação do espaço, em particular em relação aos trajetos percorridos e ao território abrangido. Os mapas individuais foram agrupados segundo essas similaridades, obtendo-se cinco padrões de espacialização chamados de Rotas.

Além de diferentes escalas de apropriações espaciais, que revelam, entre outros aspectos, as modalidades de domínio ou de controle do ambiente (MOSER, 2005, p. 17), as Rotas, como experiências geográficas, evocam uma imagem própria (DARDEL, 1990, p. 60), com uma qualidade característica.

Na Rota I, por exemplo, a imagem evocada remete ao "vilarejo", forte referência ao passado rural do local. Apesar da qualidade de um espaço rural estar presente nos outros conjuntos, neste primeiro conjunto analisado é a qualidade prevalente.

Já na Rota II - Paisagem Institucional - a imagem evocada é da apresentação oficial do bairro, com prevalência de elementos ligados ao espaço urbano.

Em relação à Rota III - a fruição estética, as relações afetivas, a valoração da história anterior ao Ribeirão Verde - sugerem uma imagem que conjuga o passado rural e o presente urbano pelos usos atuais. $\bigcirc$ "passado" é visto a partir de seu potencial atual de uso e apropriação na escala do cotidiano, inserido no contexto urbano do tempo presente, como elemento estruturador da paisagem em uma conjugação harmônica, isto é, sem clara distinção entre "a natureza" e a cidade.

A Rota IV - Vistas Panorâmicas - evoca uma imagem com vistas amplas, com forte presença de vegetação: Mata, área de preservação permanente (APP), reflorestamentos, bosques do entorno, árvores e o rio. Os marcos referenciais urbanos foram escolhidos por valores estéticos, mas principalmente pelos afetivos: assim foi selecionada a lgreja que frequenta, a escola dos filhos, as áreas de morador-em-ação. 
E, finalmente, a escala intimista, os espaços privativos, as memórias pessoais dão a Rota V - Paisagem Interior - a imagem do "lugarzinho fechado" do mundo próprio, o local do sossego e da segurança.
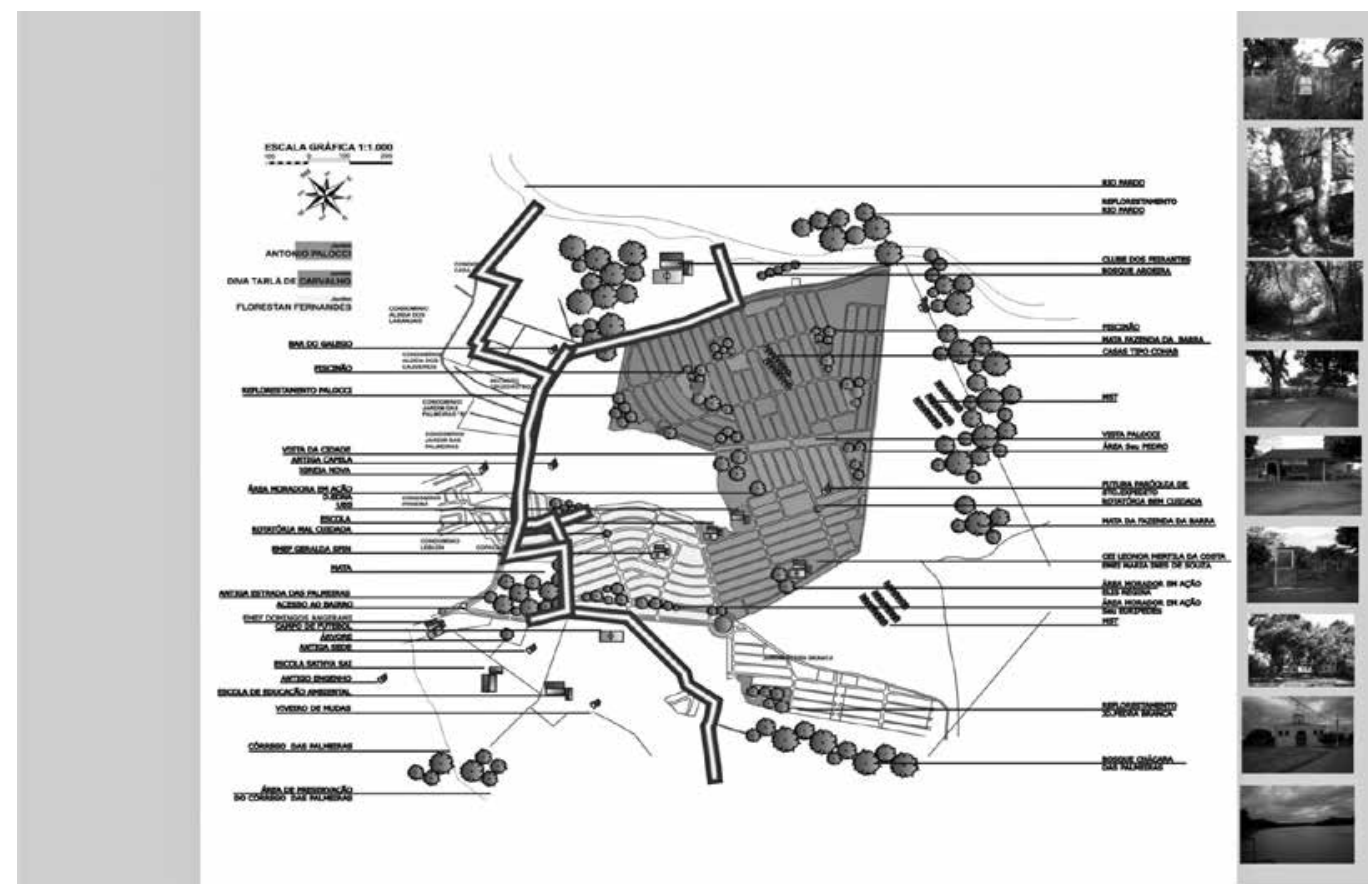

Figura 5 - Mapa de Rota I

Fonte: Autora
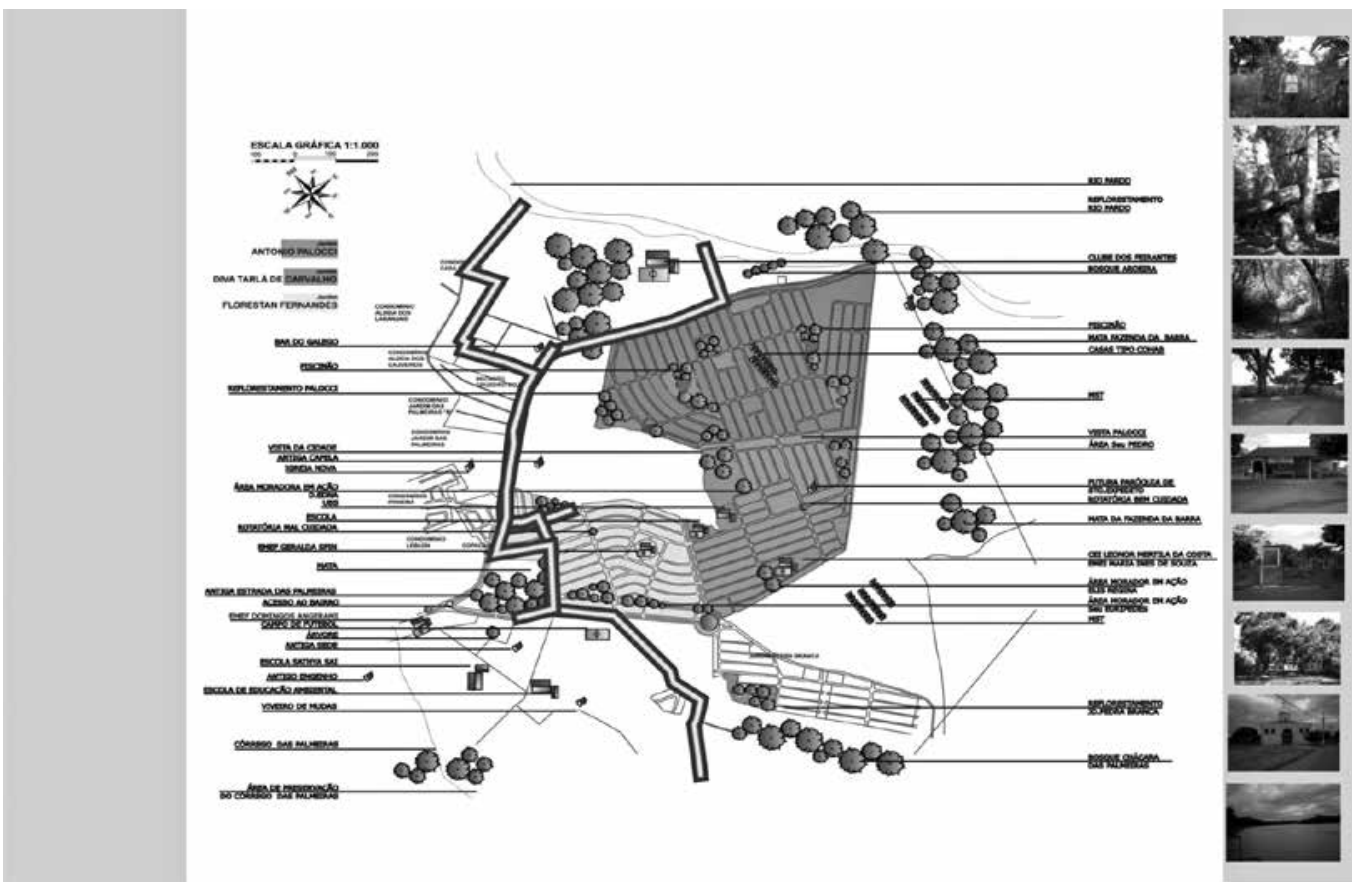

Figura 6 - Mapa de Rota II

Fonte: Autora 

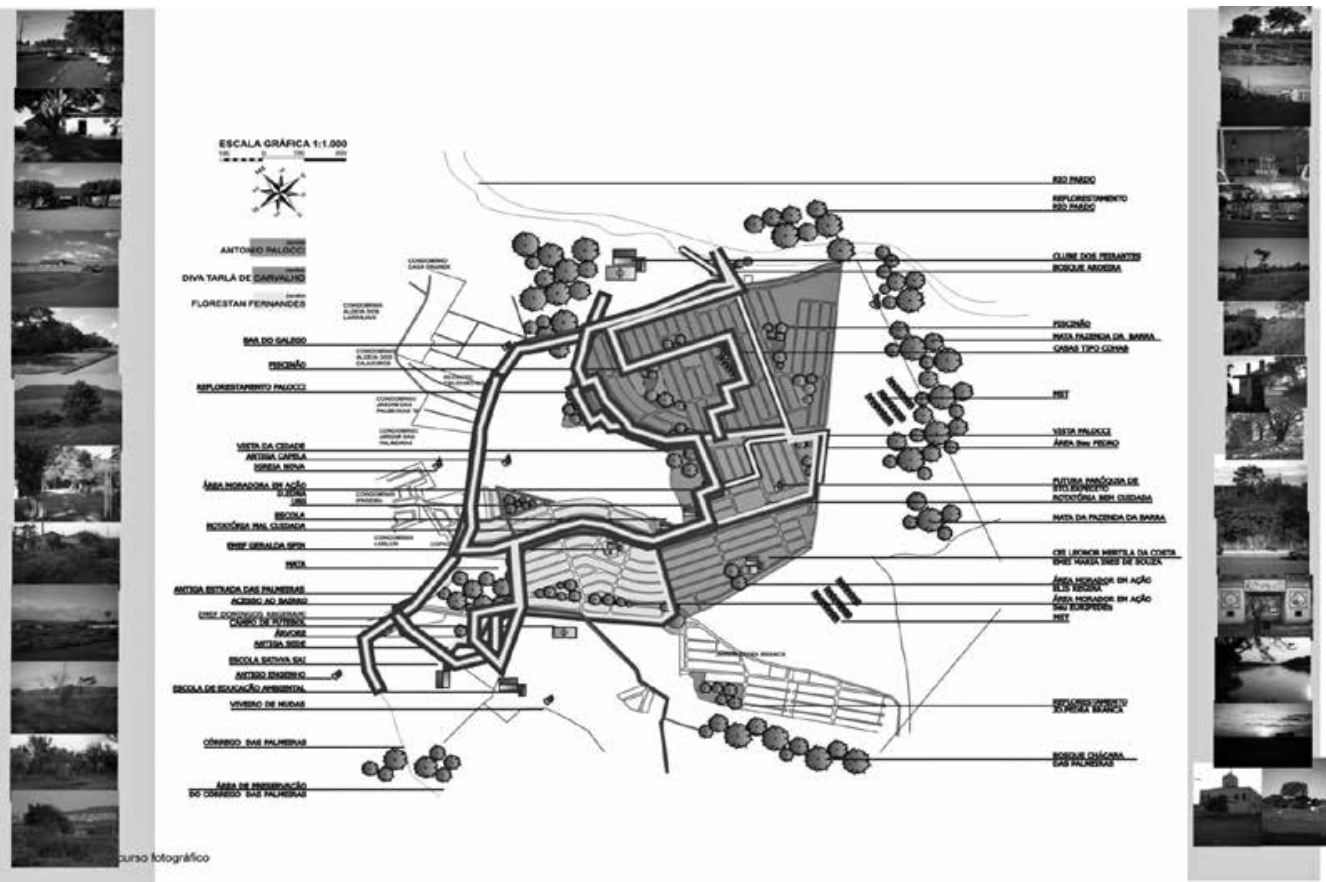

Figura 7 - Mapa de Rota III

Fonte: Autora

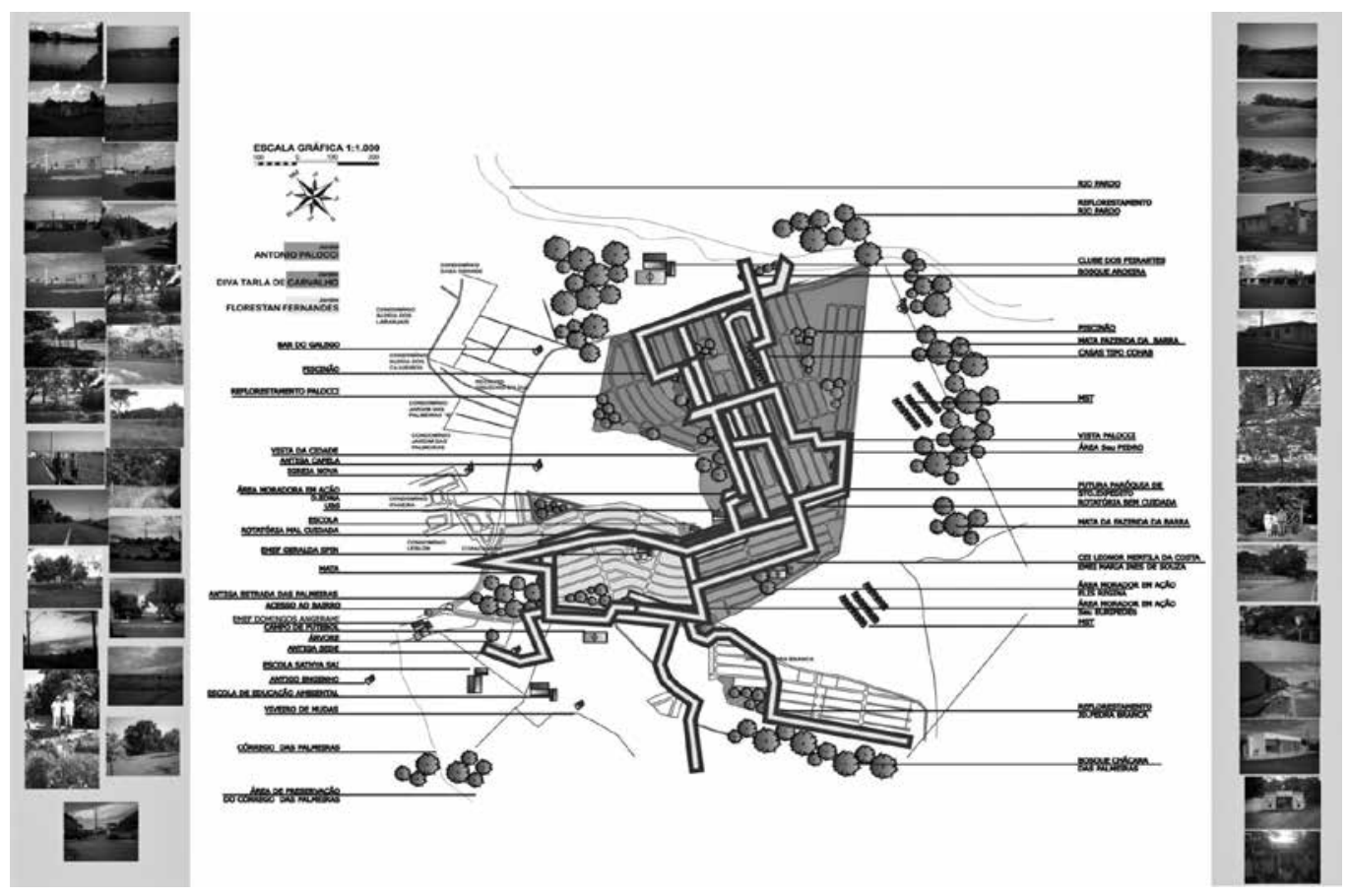

Figura 8 - Mapa de Rota IV

Fonte: Autora 


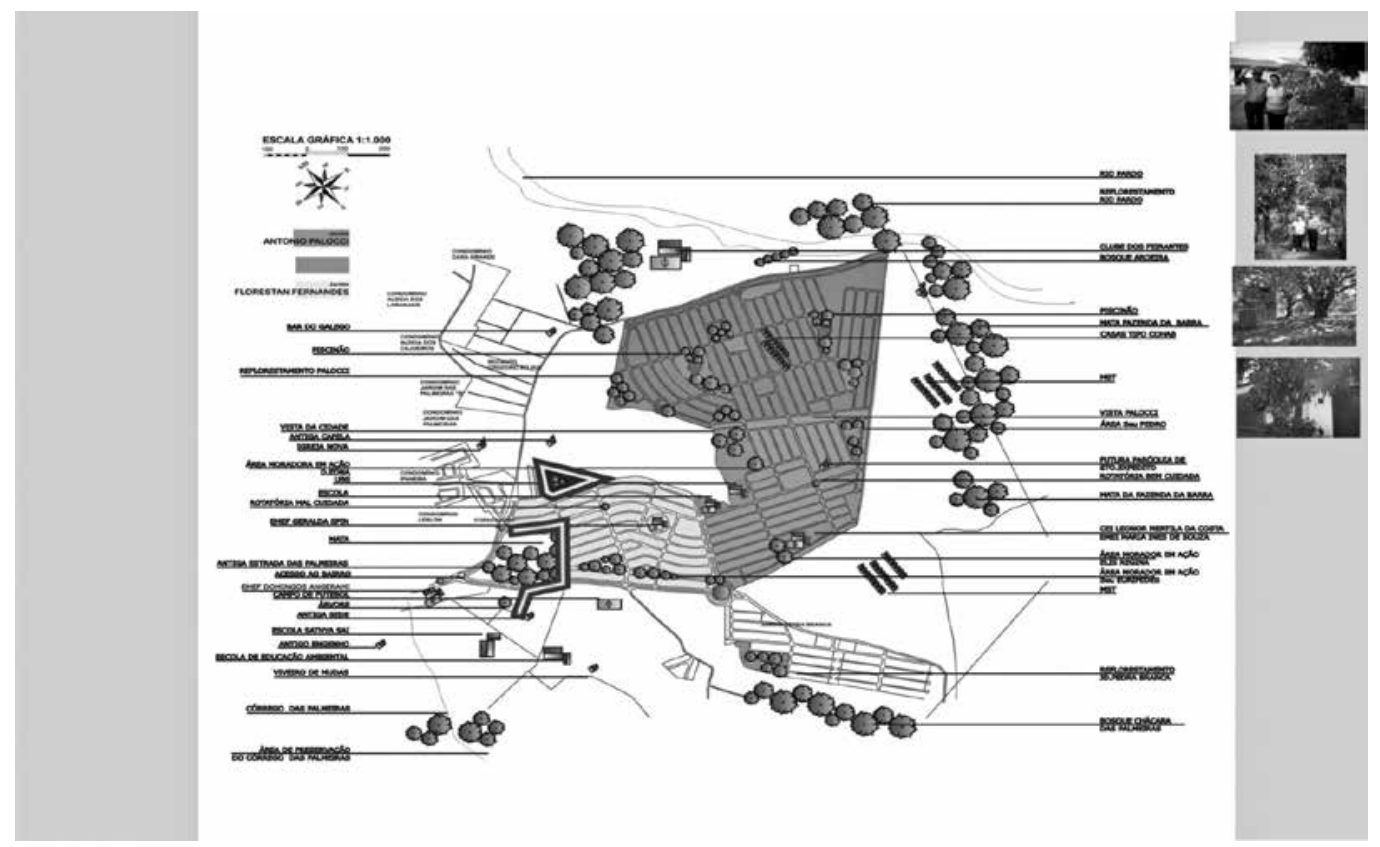

Figura 9 - Mapa de Rota V

Fonte: Autora

\section{ÁRVORE - ÁREA DE MORADOR-EM-AÇÃO E ANTIGA SEDE: VALORES DA PAISAGEM, PAISAGEM VALORADA}

Na perspectiva de Dardel, compreender uma paisagem é interpretar um significado imediatamente percebido, uma vez que pregnante ao próprio lugar. A compreensão de uma paisagem ocorre quando os diferentes aspectos ou diferentes momentos do fenômeno são reunidos na unidade de uma ideia ou imagem, que buscam no fenômeno sua característica de totalidade. Encontra-se no fenômeno percebido a unidade de um tema, de uma intenção, de tal sorte que cada aspecto iluminado por essa tradução seja compreendido como uma parte expressiva do todo ao qual ela se reporta (BESSE, 1990, p. 163).

Com fundamento nas ideias do autor citado, propõe-se considerar as cinco Rotas como diferentes traduções da paisagem percebida. Cada uma ilumina um aspecto da paisagem, sendo também parte expressiva desta, isto é, partilham da unidade de um tema. Existiria uma narrativa fundadora desta paisagem? E qual seria?

caminho encontrado foi buscar o denominador comum a todas as rotas, os marcos referenciais fotografados presentes em todas as Rotas, e encontrou-se três: área da antiga sede, árvores e área de morador-em-ação.

A área da antiga sede é uma área que pertencia ao núcleo habitacional da Fazenda Santa Maria, cedida à Prefeitura, onde atualmente está a área de lazer do bairro Ribeirão Verde. Seu conjunto de casas abriga a Associação de Moradores, a sede do Programa de Educação Ambiental (PEARV), o viveiro de mudas, a sede de uma ONG 
ambientalista, uma escola infantil particular, tendo ainda um parquinho infantil e um campo de futebol, usados pelos moradores.

Os colaboradores da pesquisa que escolheram a área da antiga sede para ser fotografada compartilham, de modo geral, a opinião de que aquele é um lugar bonito, agradável, bem arborizado e, também, que é parte da história do Ribeirão Verde. Para alguns, o lugar faz parte de suas histórias de vida.

Nos primórdios do bairro, a área da antiga sede servia de ponto de referência e ponto de apoio para os moradores, até mesmo como endereço de correspondência para o correio. Alguns colaboradores recordam-se do tempo em que o local era usado para sediar as festas juninas, as quermesses da igreja e outras comemorações do bairro, além de servir como ponto de encontro dos moradores. Com o tempo, essas atividades deixaram de acontecer. Atualmente, o local está sendo mais usado pelos moradores que têm vínculos com as instituições ali sediadas.

Uma vez que a construção da identidade do lugar ${ }^{4}$ e memória são elementos que andam juntos na construção de significados da paisagem, propõe-se pensar que a área da antiga sede "conta" aos novos moradores do local uma história sobre aquele espaço, e esse conhecimento pode contribuir para a desalienação, que significa também enraizamento.

outro marco referencial da paisagem comum a todas as Rotas são as árvores. No caso desta pesquisa os oito espécimes de árvores fotografados foram escolhidos por valores estéticos e afetivos.

Alguns colaboradores optaram por fotografar as árvores plantadas por eles, ao passo que outros por fotografar árvores frondosas, bonitas, imponentes, antigas. Mas por que fotografar árvores? $\bigcirc$ que elas indicam sobre a paisagem percebida?

As árvores são admiradas por valores estéticos, valorizadas por razões utilitárias, além de estarem ligadas a um amplo universo de simbolismos. No caso estudado, para lá de todos estes possíveis sentidos, as árvores também são signos da "natureza", representam o "verde" do bairro, e não se pode esquecer a forte valoração que plantar e cuidar de árvores tem entre os moradores-em-ação.

Em relação ao último marco referencial em comum - as áreas de moradores-em-ação - as próprias práticas de plantar, cultivar, cuidar, mostram a direção, uma vez que traz em si a imagem de enraizamento, a construção de laços de afeto com o lugar.

Tem-se, então, um conjunto que aponta para a construção de raízes, uma apropriação da história do lugar, uma harmonização com a paisagem anterior, a construção de laços afetivos com o ambiente de vida, sugerindo uma paisagem onde os sujeitos se reconhecem, e reconhecem como sua, ou são biografias tecidas com a história do bairro, dando um sentido de identidade e pertencimento (BOSI, 2004, p. 73).

\section{SENSIBILIDADE PAISAGÍSTICA}

Entre as perguntas essenciais às quais se tentou responder neste trabalho, nos limites a que se propõe, como uma primeira e abrangente aproximação a esses problemas 
complexos, foi se partilhando a princípio uma condição comum de desenraizamento em relação ao lugar, os moradores-em-ação podem, supostamente, por suas próprias ações, desenvolver uma noção de paisagem na formação de uma "sensibilidade paisagística", de uma certa noção de paisagem.

Apoiando-se na delimitação de noção de paisagem como a percepção de um conjunto, que é mais que a soma de seus componentes, que encerra certo investimento afetivo e ao qual se atribui um valor estético, acredita-se que eles possam estar desenvolvendo uma noção de paisagem que se aproximaria antes do espaço objetivo da existência, que uma vista abarcada pelo sujeito.

Retoma-se a própria história dos usos do termo. A palavra landschap (neerlandês), landschaft (alemão), paese (italiano) antes de adquirir uma significação, sobretudo estética ligada ao gênero específico de pintura a partir dos séculos XVII e XVIII, tem uma significação que se pode dizer territorial e geográfica (BESSE, 2006, p. 20).

Tomada em um sentido jurídico-político e topográfico, a paisagem é de início a província, a pátria, a região. Nessa perspectiva geográfica, a paisagem não é definida de início como a extensão de um território que se descortina num só olhar de um ponto de vista elevado, mas espaço objetivo da existência, mais do que uma vista abarcada pelo sujeito (BESSE, 2006, p. 20). Um landschaft define-se por seu sitium, isto é, uma posição e uma vizinhança características, designadas como objetivas, que podem ser cartografadas por sua qualidade ou natureza própria, um conjunto de propriedades naturais ou humanas.

O termo landschaft e seus cognatos eram usados para descrever regiões administrativas no noroeste da Europa. Essas sempre foram regiões relativamente pobres, marginais aos interesses de monarcas e aristocratas, cujas riqueza e poder dependiam do controle, propriedade e tributação dos territórios mais férteis e acessíveis. A localização dessas regiões em zonas fronteiriças reforçou as oportunidades para maior autonomia local do que em regiões mais centrais e bem administradas ${ }^{5}$

A hipótese do desenvolvimento de uma noção de paisagem pelos moradores-em-ação, que se aproxima da noção de landschaft, encontra subsídios nos dados empíricos coletados.

Primeiro, encontra-se no bairro Ribeirão Verde uma situação de isolamento, propícia ao desenvolvimento de autonomia social e territorial. Periferia de uma cidade média que guarda certas semelhanças com as "regiões distantes - relativamente empobrecidas, fronteiriças e marginais aos interesses dos monarcas e governantes".

Nos depoimentos colhidos há várias indicações da percepção dos moradores de não pertencimento à cidade, sujeitos a carências materiais e imateriais. Mas ao mesmo tempo, o depoimento dos colaboradores revela a percepção de que não pertencer à cidade de Ribeirão Preto pode ser algo favorável, talvez morar em uma "cidadezinha do interior", um lugar calmo, menos violento, bom de se viver, mais fresco, mais amplo, com mais lugar para se viver, solidário, quando comparado aos outros bairros nos quais moraram ou que conheceram. Alguns colaboradores chegam até a sonhar com a "independência do bairro" de Ribeirão Preto. 


\section{CONSIDERAÇÕES FINAIS}

A pesquisa realizada ressaltou que, ao se tratar de questões de conservação de recursos naturais e preservação de áreas protegidas envolvendo população, além das ações normativas e técnicas, é necessário que se leve em conta as pessoas envolvidas. Sejam reservas legais, áreas de preservação permanente ou recursos naturais, entende-se que esses elementos objetivos da paisagem não devem ser tratados como objetos isolados, mas pensados como elementos articulados em um conjunto, uma trama narrativa, uma história que faça sentido para as pessoas para quem essa paisagem existe. É preciso, pois, que os elementos da paisagem sejam reunidos em um conjunto significativo, "um tema".

Se, no entanto, a realidade das coisas não lhes é inerente, e, sim, inerente à nossa relação com as coisas (BERQUE, 1994), e cada indivíduo determina a própria paisagem pela identificação de algumas relações e possíveis significados entre os diversos elementos que a compõe, como propor um substrato paisagístico que acolha tanto as "áreas de preservação", os aportes dos sujeitos e a conservação dos recursos naturais?

Uma direção pode estar em substratos paisagísticos plásticos, receptivos, que possam acolher a heterogeneidade dos moradores, seus aportes e diferentes usos e apropriações - materiais, afetivos, simbólicos. Uma proposta em que as diversas escalas - material, social e mental - sejam articuladas ou, em outras palavras, as medidas normativas, técnicas e educacionais, sejam articuladas com as subjetividades, e mediadas por um substrato paisagístico fértil, onde o habitar poético possa florescer. É preciso, pois, pensar em termos de paisagem, isto é, relações, e não em termos de objetos isolados.

No que diz respeito aos estudos de paisagem vale destacar que, para se aproximar da paisagem percebida por um grupo de pessoas, é preciso tentar conhecer o que elas valorizam, onde encontram significado, como são afetadas por aquele ambiente de vida. Conhecer uma paisagem não se esgota nem em abordagens objetivas, nem em abordagens psicológicas. A paisagem,volta-se a dizer, é trajetual, é tanto matéria quanto espírito. E é nessa ambiguidade constituinte da paisagem, sujeito e objeto, representação e representado, marca e matriz, que se encontra seu sentido profundo (BERQUE, 2008, p. 69).

\section{Notas}

1 Sobre as criações dos moradores-paisagistas ver LASSUS, Bernard. Jardins Imaginaires. Les habitants paysagistes, 1977.

2 Sobre a noção de substrato paisagístico ver FERRIOLO, Massimo, 2006, p. 95.

3 Um dos "Percursos Fotográficos" foi feito por duas colaboradoras.

4 Sobre o papel do ambiente construído na constituição das identidade pessoal e social ver Proshansky, Ittelson e Rivlin (Orgs.). Environmental psychology: man and his physical setting. Nova York: Holt Rinehart \& Winston, 1976.

5 COSGROVE, Denis. Landscape and Landschaft. Spatial Turn in History Symposium German Historical Institute, February 19, v. 35, 2004. Disponível em: <http://www.ghi-dc.org/publications/ ghipubs/bu/035/35.57. pdf >. Acesso em: 8 fev. 2010. 


\section{Bibliografia}

BERQUE, Augustin. La pensée paysagére. Paris: Archibooks Sautereau.Editeur, 2008.

. Mediance. Paris: Belin, 2000.

BESSE, Jean. Marc. Ver a terra: Seis ensaios sobre a paisagem e a geografia. Trad. Vladimir Bartalini. São Paulo: Perspectiva, 2006.

Géographie et existence. In: DARDEL, E. L’homme e la terre: Nature de la réalité géographique. Paris: $\overline{\text { Editions }}$ du CTHS, 1990, p. 135-175.

BOSI, Ecléa. O tempo vivo da memória: Ensaios de psicologia social. São Paulo: Ateliê Editorial, 2004.

CRITELLI, Dulce Maria. Analítica do sentido: Uma aproximação e interpretação do real de orientação fenomenológica. São Paulo: Brasiliense, 2006.

DARDEL, Eric. L' homme e la terre : Nature de la réalité géographique. Paris. Editions du CTHS, 1990 p. $135-175$.

FERRIOLO, Massimo Venturi. Paesaggi rivelati. Passeggiare con Bernard Lassus. Milão: Guerini e Associati, 2006.

GOLDENBERG, Mirian. A arte de pesquisar: Como fazer pesquisa qualitativa em Ciências Sociais. Rio de Janeiro: Record, 2005.

ITTELSON, William. Environment and cognition. Nova York: Academic Press, 1973.

; PROSHANSKY, H.; RIVLIN, L.; WINKEL, G. H. Homem ambiental. Textos de psicologia ambiental do Instituto de Psicologia. Universidade de Brasília. Brasília: Editora da UnB, 2005.

LASSUS, Bernard. Une poétique du paysage: le démesurable. In: Le Dantec : Jardins et paysages. Paris: Larousse, 1996.

Jardins imaginaires. Les habitants paysagisties. Paris: Les Presses de la Connaissance, 1977.

MOSER, Gabriel; WEISS, Kate. Espaces de vie aspects de la relation homme-environnent. Paris: Armand Colin/ VUEF, 2003.

PROSHANSKY, Harold; ITTELSON, William; RIVLIN, Leanne (Orgs.). Environmental Psychology: Man and his Physical Setting. Nova York: Holt Rinehart \& Winston, 1976.

RAPOPORT, Amos. Aspectos humanos de la forma urbana: Hacia uma confrontación de las ciencias sociales con el diseño de la forma urbana. Barcelona: Gustavo Gilli, 1978. 
